\title{
Flipped Classroom: Letting Students Take Control of Their Study
}

\author{
Yuxian Zhao \\ Queens University Belfast, School of Social Science and Education, Belfast, Northern Ireland, United \\ Kingdom, BT7 1NN \\ Email: 542588585@qq.com
}

Keywords: teaching strategy, flipped classroom, self-regulated learning, lifelong learners

\begin{abstract}
All in all, flipped teaching is an effective strategy to improve students' academic achievements. It strengths are obvious when the learner is highly motivated and interested. It can give better chances to pupils from disadvantaged social, cultural, and economical areas, if they have obtained the skill to operate basic technologies. Salman Khan (2014) states "we can all become better learners; we just need to build our brains in the right way". So it is important to teach students to gain the ability of self learning, which will bring the best for everyone in the long run. It also requires parents' supervision when students are not able to self regulate themselves. At the same time, teachers are equally important in a traditional classroom because the power of role models can not be overlooked. Sometimes, children start to be interested in one subject because of their teacher's attitude. Teachers who express enthusiasm are more likely to keep their students motivated (Mary Dennis (2012)). Most educators tend to believe that education in the future will be more personalized and student led (The U.S. Department of Education Office of Educational Technology (2016)). Teachers, families, and society will need to work together to make this happen.
\end{abstract}

\section{Introduction}

\subsection{The Concept of Flipped Classroom}

For so many years, some educators have been trying to seek alternative pedagogy apart from lecture-based traditional teaching. In traditional classroom settings, the teacher is the center of the classroom, and students follow instructions, take notes, and then bring assignments or exercises home. Often, a number of students with different cognitive levels and interests share the same classroom and teaching style (Goodwin \& Miller (2013)). For some students, who can follow perfectly, it is suitable enough for them to make progress. While for others, who are far advanced or left behind, it can be either boring or cause struggling. Lecture-based teaching produces passive learning attitudes (needs cite). Pupils might find it hard to take information intensively and constantly in the fixed time (Ibrahim, M. \& Callaway, R. (2014)).

A new notion of teaching caught a large number of schools and educators' attention over the last two decades. Flipped teaching is a strategy that turns the traditional classroom upside down by delivering instructional knowledge or concepts outside of the classroom; therefore, moving homework and activities into the classroom. Students will watch online lectures, videos, and participate in online discussions before going to school. They may also have to do research or reading at home and be devoted to active learning related to the concept in class with the tutor (Wikipedia, Flipped classroom). This may allows teachers more flexibility in dealing with the needs of their students through projects, group-based activities and exercises because they can save time by letting student utilize lectures and instructional content via online videos before class.

\subsection{The Rise of Flipped Classroom}

The approach of 'focusing on the importance of the use of class time for the construction of meaning rather than information transmission (Alison King (1993))' was pointed out in the early 90s. With the development of technology such as YouTube, VCRs, and other types of media, it has made it more convenient and possible in practice. The data from the Flipped Learning Network 
(2012) illustrated that membership on its social media site have grown from 2,500 to 9,000 teachers from 2011 to 2012.

Probably one of the most remarkable contributors to flipped teaching is Salman Khan because his Khan Academy has been a role model for so many schools who share the same belief. Although it only contains one part of flipped classroom, it provides resources and sets a great example for education organizations all over the world. Many higher education courses (Arnaud, C. H. (2013) ) and K-12 classrooms (Bergmann, J. \& Sams, A. (2012)) have been adopting this approach to reverse the classroom in order to overcome the restrictions of the traditional classroom ( Steed, Anthony (2012)).

\subsection{Conclusion}

Flipped classrooms are a student centered approach based on modern technology and when compared to traditional classrooms, it seems to have advantages; however, some experts disagree and question the quality of learning when students control part of it (Andy Farquharson (1997)). This essay will address the impact of flipped classrooms and evaluates educational products, such as academic achievements, pupils' engagement, motivation, promoting self directed studying, and equality. Furthermore, the limitations of flipped classrooms will be pointed out.

\section{Literature Review}

\subsection{Historical review}

According to John Dewey (1907), our traditional education system is factory like, and he stressed student centered learning rather than direct instructions or other single limited approaches because teacher centered teaching system, which delivers instructional information based on memorization and standardized materials, can no longer satisfy the growing diversity of student demands in the classroom; thus, interpersonal and intrapersonal learners might not appreciate the same pedagogy (F. Jill \& M. Dee (2012)). Therefore, taking students’ personalities and interests into account is fundamental for educational success. It is the educators' responsibility to deliver efficient, suitable and enjoyable lessons. Dewey also argued that children will take the most advantage of the knowledge when they interact with the environment and engage with school curricula (D. John (1944)). It is important for them to learn by doing and experiencing, and the teacher centered educational style might not provide enough of this.

Knowledge is powerful (Y. Micheal (2014)) and the ubiquitous of technology and the internet has provided a simple and affordable way to aggregate information. It explains the natural and social worlds and helps us to understand them beyond an individuals' experience. Powerful knowledge is not the same as common knowledge, which students can pick up during daily life, because it allows pupils' intellectual power to see beyond and perhaps supply alternatives for their future life (M. Alaric Maude (2015)). People with more powerful knowledge often have greater influence to the world. Schools and teachers should ensure every child has the same opportunity to acquire the same education because one function of education is to guide students to build their own moral and intellectual perceptions, for whom do not have the access to it. Powerful knowledge needs to be available for all children in different countries and from all social and cultural backgrounds, otherwise education would be unfair and unjust.

The purpose of education should be to help people determine how to learn on their own (C. Noam (2013)) and become life long learners. As a result, it will also be beneficial for our society as a whole. This requires them to get into an open-ended and continuous learning process (C. Offe \& P. Ulrich (1991)). In this case, research skills and study abilities are more significant for children than test results and academic achievements. Students themselves decide what to learn and how they are going to master it. Furthermore, they decide achievements, and personal plans freely and independently while teachers act as helpers to assist them in this process. Pupils, teachers and parents work collaboratively to reconstruct the curriculum to engage everyone. The layout of a classroom will be completely different. Democratic educationists believe that self-determination 
and democratic governance (IDEC (2005)) are essential in the educational process. Education is about young people and their voices should be heard. It is good for students to be able to choose what they like to learn and manage their study plans and schedules (Peter Hutton (2014)), thus, becoming a more a personal experience.

In functionalists' perspectives, education is seen as a functional prerequisite because it passes on the culture of a society, particularly its core value, and provides a trained and qualified labour force ( $\mathrm{C} \mathrm{H}$ Thompson (2008)). While the job market has changed due to the progress of science and technology, jobs in the next twenty or fifty years will not be anything like what people have been familiar with so far (Gov.UK (2014)). For instance, most of people 70 years or older only had one job in their life time; the generation between 40 to 60 years old normally have one to three jobs before retirement, but, when it comes to younger generations, it is likely they have changed their occupations a few times before middle-age ( The Guardian (29 Nov 2015)). The next generation is facing a world with multiple challenges and opportunities that no one has ever seen before. Schools should adjust curriculum to catch up with social changes. Many people now live in a society where working, learning and entertaining are done by digital devices. Even young children now play online games and watch videos, so it is important for educators to consider bringing these elements into the classrooms.

\subsection{Conclusion}

Technology today is not just causing change but accelerating it and knowledge is growing at an exponential rate. Students do not only need to learn new subjects, but also need to relearn the outdated truth (Alvin Toffler (1970)). That means teachers have to help pupils to learn efficiently and effectively, so they can equip themselves with new knowledge and skills to easily adapt to a changing environment. Learning can be individualistic and teachers need to help young people explore and optimize their own styles. For instance, visual, auditory, kinesthetic, social, and solitary learners use different strategies acquire knowledge (Time4learning). For that reason, once the learning style is identified, it should be the teachers' responsibility to assist the child in developing it further.

It is worth mentioning that the way of obtaining knowledge has shifted from libraries to the Internet (Tait et al. (2016)), and most students in the world can access it at any time and any place, which promotes equality in education. Since educators goals are to help young people to achieve their own potential (L. Meira Levinson (2002)), the roles of teachers and students will not be the same as before. Consequently, education is experiencing a global revolution. Noam Chomsky (2012) argued in his speech, that technology in education is like a hammer ---- it can build or kill . The Internet can be quite valuable if individuals know what they are looking for.

\section{Evaluating Flipped Classroom}

\subsection{Improving academic achievements}

Lectures in flipped classroom can be replayed multiple times, so it should help pupils to understand key concepts and information better. This can allow students to work on problems they face and not concepts in class with the help of their teacher and other students. A research done by Virginia University (Cheryl P. Talley \& Stephen Scherer (2013)) has proved that flipped teaching improved students' academic outcomes by $10 \%$ in a psychology course and when flipped classrooms were not used in mathematics and science subjects, the gap caused by traditional learning techniques were significant. . Figure 1 shows the results of two groups of second-year students from Portugal selected by different pedagogical approaches participated in flipped classroom obtained scores that were two letters higher than the other students in the traditional classroom (Ana P. Lopesa \& S. Filomena (2018)). Furthermore, students are having a more positive experience in flipped classrooms because online lectures were quite helpful, and they enjoyed more of the hand-on activity-based learning (Cheryl P. Talley \& Stephen Scherer (2013)). 


\begin{tabular}{llll}
\hline & $2014 / 2015$ & $2015 / 2016$ & $2016 / 2017$ \\
\hline Flipped Classroom success rate & $71,4 \%$ & $90,5 \%$ & $91,2 \%$ \\
Traditional Classroom success rate & $49,2 \%$ & $62,3 \%$ & $62,7 \%$ \\
\hline
\end{tabular}

Figure 1

\subsection{Improving students’ engagement}

Students do learn better when they enjoy the content and process (needs cite). Research shows that storing information into long-term memory is more successful when learners are emotionally engaged (P. Herbert Puchta (2012)) and flipped classrooms require more engagement. By exchanging lectures with exercises, activities and projects, it transforms the classroom into an active learning atmosphere by having more cooperation and interaction during exercises. This also allows pupils to learn by doing and from peers and increases students' confidence as well as reduce their anxiety. At the same time, deeper learning is being promoted when pupils can explore further on the topic with the guidance of a tutor. The teacher can prompt them to reflect on their learning and thinking (Shelley wright (2012)). Many students find it easier to ask questions in a flipped classroom setting (Kahu (2013)). That makes teachers focus more on individual students rather than the knowledge transmitted (Steen-Utheim, A. T. \& Njal, F (2017)). This creates a relationship between students and teachers that is less hierarchical because teachers no longer act as class instructors, but as monitors to assist learners to achieve their goals.

\subsection{Meeting the needs of all learners}

Another noteworthy benefit is that students can watch the videos at their own preferred time and speed. Considering the various cognitive levels and learning pace of students, it is efficient for everyone. The teacher does not have to repeat herself for the ones who do not understand or add extra pieces for advanced students. Each learner can choose to learn according to their current known knowledge. Even for learners with short attention spans, they can pause the videos when a break is needed (Mary Rooney (2017)).

In a flipped classroom, every student's uniqueness is valued. The possibility of giving them videos which interested them is greater than delivering a lecture satisfying thirty or more of them at once.

\subsection{Promoting education equality}

Parents' social, economical and educational backgrounds have huge impacts on their children's learning outcomes (Kean, D \& Pamela E. (2005)). In flipped classrooms, students from all backgrounds can be watching the same videos even if they are going to different schools such as one high School in Clintondale, United States that inspired all schools from lower economic areas by using online lectures made by the most recognized teachers in each area; therefore, the children actually received the same education as the ones from better schools (Greg Green (2012)). This type of learning enables students across social classes, neighborhoods, and districts to share the best resources, and the cost for electronic devices is much less compared to hiring a teacher. It opens opportunities for students even from the third countries. For example, a student from Africa can learn mathematics from a teacher in America. Flipped classrooms give an affordable and accessible way to promote education equality all over the world.

\subsection{Promoting self-directed studying}

Self-direction is a crucial skill in child-centered educational. It is also important for individuals as our society desire life-long learners. Life-long learners are the people who can identify their learning goals, find appropriate resources, set research plans and apply their knowledge into practice. Comparing with the ability to find their own resources, absorbing the content is less important. When students take the initiative with or without support from educators or parents, self-directed learning occurres (Alamry, A. \& karaali, A (2016)). In flipped classrooms, students 
watch short videos or lectures before class without the supervision of a teacher. This level of self-regulation can be critical (Shyr, W. J. \& Chen, C.H. (2017)) because students are not always successful in regulating their own learning, especially in technology-based learning environments (Lee, et al. (2009)). Actually, before students can achieve self-direction, instructions such as modeling, coaching, and appropriate reinforcement might be needed to establish this new behaviour (Bannert, M. \& Reimann, P. (2011)). Flipped lecture is still a lecture, so it is unlikely for children, who do not pay attention in the lecture hall, to start taking the videos seriously. For some students, they might treat these videos just like homework.

\section{Limitations of Flipped Classroom}

A flipped classroom is not a perfect formula to solve all of the educational problems. Just like many other approaches, it has its limitations. Figure 2 lists explains that it is not easy to keep everyone on the subject once students take control of their own studies, and the success of this strategy strongly relies on the willingness of students (DU et al. (2014), so motivation plays a key role in achieving full potential. Without motivation, poorly performing students might actually become worse in a flipped classroom, further widening the gap between them and more motivated students. Especially for students that need to get stimulus from a teacher's order. Teachers also face a difficult task for assessing learning. In addition, poverty stricken learners might not have access to technological devices or reliable Internet. Another potential issue could be the over use of digital devices, with students coming reliant on them.

\section{Reflection on Flipped Classroom}

I found other elements that effect learning through my experience with a 4-year-old boy. We have 30 minute English lessons each week from Tuesday to Friday on an application software called QQ that provides video chatting. I send him some cartoons or songs before class, and then we play games and practice on QQ. Within one month, his progress had exceeded my expectations. I found that his mother is essential in his success because she is deeply involved in his learning process. She makes sure her son watches the short cartoons and clips before the lesson begins, and takes videos of him performing according to the skills he masters. However, not all students will have the same support at home, so we should not leave the context out when evaluating the effectiveness of this teaching method.

In another example with middle school girls in rural area of China, the outcome was not as positive. Students showed passive attitude towards to flipped learning environment, and lacked the motivation required to make sufficient progress. If we take into account these teenagers from the countrysides' lack of experience with modern technology, they might also be at a disadvantaged even when video lectures are provided. This could be the reason for their negative attitude when it comes to previewing the key concepts.

\section{Flipped Classroom with Other Educational Approaches}

As mentioned in this paper, flipped classrooms with behaviour analysis can build consistent self study. Once the new behaviour is established, pupils will profit from it over their life time. Furthermore, parental involvement can significantly improve children's performance (Desforges, C. \& Abouchaar, A. (2003)). With help at home, the effectiveness of flipped learning will be maximized.

\section{Conclusion}

All in all, flipped teaching is an effective strategy to improve students' academic achievements. It strengths are obvious when the learner is highly motivated and interested. It can give better chances to pupils from disadvantaged social, cultural, and economical areas, if they have obtained 
the skill to operate basic technologies. Salman Khan (2014) states "we can all become better learners; we just need to build our brains in the right way". So it is important to teach students to gain the ability of self learning, which will bring the best for everyone in the long run. It also requires parents' supervision when students are not able to self regulate themselves. At the same time, teachers are equally important in a traditional classroom because the power of role models can not be overlooked. Sometimes, children start to be interested in one subject because of their teacher's attitude. Teachers who express enthusiasm are more likely to keep their students motivated (Mary Dennis (2012)). Most educators tend to believe that education in the future will be more personalized and student led (The U.S. Department of Education Office of Educational Technology (2016)). Teachers, families, and society will need to work together to make this happen.

\section{References}

[1] Adel Alamry \& Abeer karaali, 2016,Flipped education: Transitioning to the homeschool environment

[2] Alaric Maude, 2015, What is Powerful Knowledge and Can It Be Found in the Australian Geography Curriculum?

[3] Alison King, 1993, 'focusing on the importance of the use of class time for the construction of meaning rather than information transmission

[4] Ana Paula Lopesa \& Filomena Soares, 2018,Perception and performance in a flipped Financial Mathematics classroom

[5] Andy Farquharson, University of Victoria, 1997, Enhancing the self-directed learning skills of students entering practica

[6] Anna Therese Steen-Utheim \& Njal Foldnes, 2017, a qualitative investigation of student engagement in a flipped classroom, Teaching in Higher Education, 23:3, 307-324, DOI: 10.1080/13562517.2017.1379481

[7] Arnaud, C. H., 2013, Flipping chemistry classrooms: Professors shift lectures online to free up class time for more effective learning activities. Chemical and Engineering News, 91, 41-43.

[8] Bannert, M., \& Reimann, P., 2011, Supporting self-regulated hypermedia learning through prompts. Instructional Science, 40(1), 193-211. doi:10.1007/s11251-011-9167-4

[9] Bergmann, J., \& Sams, A., 2012, Flip your classroom: How to reach every student in every class every day. Washington, DC: International Society for Technology in Education.

[10] Berlin, IDEC 2005. "IDEC 2005 - Documentation". en.idec2005.org. Retrieved 27, Dec 2017.

[11] Careers of the future, 2014, Gov.UK

[12] Charles Desforges \& Alberto Abouchaar, 2003, THE IMPACT OF PARENTAL INVOLVEMENT, PARENTAL SUPPORT AND FAMILY EDUCATION ON PUPIL ACHIEVEMENT AND ADJUSTMENT: A LITERATURE REVIEW

[13] Cheryl P. Talley \& Stephen Scherer, 2013, The Enhanced Flipped Classroom: Increasing Academic Performance with Student-recorded Lectures and Practice Testing in a "Flipped" STEM Course

[14] C. H. Thompson, Dec 2008, https://sociologytwynham.com/2008/12/20/what-is-the-point-of-education/

[15] Davis Kean \& Pamela E., The Influence of Parent Education and Family Income on Child Achievement: The Indirect Role of Parental Expectations and the Home Environment, Journal of Family Psychology, Vol 19(2), Jun 2005, 294-304

[16] Dewey, J., 1907, "The School and Social Progress." Chapter 1 in The School and Society. Chicago: University of Chicago Press: 19-44.

[17] Dewey, J., 1944, Democracy and education. New York: the Free Press 
Elizabeth Tait, Konstantina Martzoukou\& Peter Reid, 2016, Libraries for the future: the role of IT utilities in the transformation of academic libraries

[18] Goodwin, B. \& Miller, K., 2013, September, Grit + talent = student success. Educational Leadership, p. 74-76.

[19] Greg Green, 2012, My View: Flipped classrooms give every student a chance to succeed, address:http://schoolsofthought.blogs.cnn.com/2012/01/18/my-view-flipped-classrooms-give-every -student-a-chance-to-succeed/comment-page-2/

[20] Herbert Puchta, 2012, Developing Thinking Skills in the Young Learners’ Classroom

[21] Ibrahim, M. \& Callaway R., 2014, Students' Learning Outcomes and Self-efficacy Perception in a Flipped Classroom

[22] Jill Fernando and Dee McCarney, 2012, Learning Styles and Learning Preferences,

[22] KAHU, E. R. (2013) Framing student engagement in higher education. Stud. Higher Edu., 38, 758-773. 